\title{
Hypopharyngeal and Parapharyngeal Space Metastasis of Papillary Thyroid Carcinoma: A Case Report
}

\author{
Ayşegül Batıoğlu-Karaaltın, Elad Azizli², İlker Ersözlü${ }^{3}$ Özgür Yiğit ${ }^{1}$, Harun Cansız ${ }^{4}$ \\ ${ }^{1}$ Department of Otolaryngology Head and Neck Surgery, İstanbul Education and Research Hospital, İstanbul, Turkey \\ ${ }^{2}$ Department of Otolaryngology Head and Neck Surgery, MediEnt Hospital, İstanbul, Turkey \\ ${ }^{3}$ ETA Pathology, İstanbul, Turkey \\ ${ }^{4}$ Department of Otolaryngology Head and Neck Surgery, İstanbul University Cerrahpasa Faculty of Medicine, İstanbul, Turkey
}

\begin{abstract}
Background: Carcinoma of the thyroid gland is one of the most commonly encountered endocrine malignancies. Papillary carcinoma is the most common histological type, and its spread is usually lymphatic. About $30-80 \%$ patients with papillary carcinoma develop lymphatic metastases.

Case Report: We present here the case of a 70-year-old female patient who had undergone total thyroidectomy 10 years previously, with a histological diagnosis of papillary thyroid carcinoma. A neck dissection was performed ten years after the primary operation due to a mass in the parapharyngeal space and hypopharynx. The mass was diag-
\end{abstract}

nosed histologically as papillary thyroid cancer metastasis after the operation.

Conclusion: Lymphatic and vascular metastases of papillary thyroid carcinoma separately to the parapharyngeal space and hypopharynx have rarely been reported. In our case, both hypopharyngeal and parapharyngeal space involvement were presented, which is a very rare condition.

(Balkan Med J 2014;31:177-9).

Key Words: Hypopharynx, metastasis, parapharyngeal space, thyroid carcinoma
Carcinoma of the thyroid gland is one of the most commonly encountered endocrine malignancies (1). Among all of the thyroid malignancies, papillary carcinoma is the most often encountered histological type and its pattern of metastasis is usually lymphatic (2). Around $30-80 \%$ of patients with papillary carcinoma develop lymphatic metastases (3). Haematogenic and distant metastases seem to be rare but, if present, the bone, lungs, skin, and brain are the most common localisations. Involvement of the recurrent laryngeal nerve, larynx, pharynx, trachea, and oesophagus occurs through direct infiltration $(4,5)$.

Metastasis to the hypopharynx and parapharyngeal space seems to be straightforward due to the close anatomical localisation, but a few cases of parapharyngeal $(6,7)$ and hypopharyngeal involvement $(8,9)$ have appeared in the literature. In our case, we present papillary thyroid carcinoma metastasis involving both the hypopharynx and the parapharyngeal space.

\section{CASE PRESENTATION}

A 70-year-old female patient was referred to our clinic with dysphagia and dyspnoea. The patient had undergone a total thyroidectomy ten years previously and the histological diagnosis was papillary thyroid carcinoma. Eight years after this surgery, a left modified radical neck dissection had been performed and histological examination showed papillary carcinoma metastasis in three lymph nodes. Indirect laryngoscopy revealed a sub-mucosal mass in the left lateral pharyngeal wall, which extended towards the midline. The larynx was deviated to the right and the left vocal cord was paralytic. Axial MRI section of the neck revealed a mass that was $2.4 \times 1.3 \mathrm{~cm}$ in size narrowing the airway in the lateral wall of the hypopharynx. Sagittal MRI section of the neck showed that the mass was lining from the tracheal cartilage level to the parapharyngeal space (Figure 1). The tumour was dissected upwards from the left sinus pyriformis and the great horn of the thyroid cartilage through the retropharyngeal space to the parapharyngeal space and the base of the skull. The $10 \mathrm{~cm}$ long tumour was excised totally (Figure 2). The hypopharyngeal defect was repaired with primary sutures. A histopathological evaluation showed a papillary structure under the epithelium. The diagnosis was a papillary carcinoma metastasis (Figure 3). Informed consent was taken from the patient. 


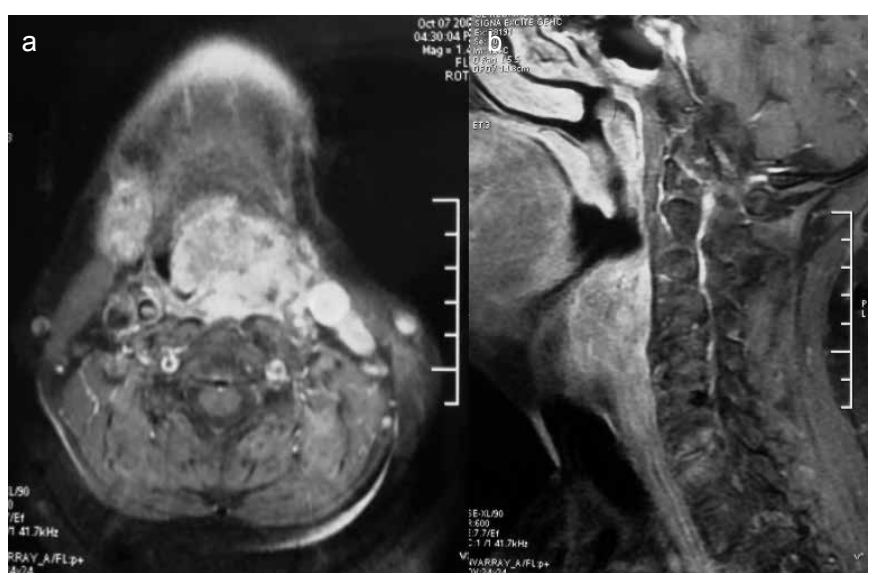

FIG. 1. A mass with a size of $2.4 \times 1.3 \mathrm{~cm}$ narrowing the airway was observed in the lateral wall of the hypopharynx on axial MRI section of the neck (a). Sagittal MRI section of the neck showed a mass lining from the tracheal cartilage level to the parapharyngeal space (b).

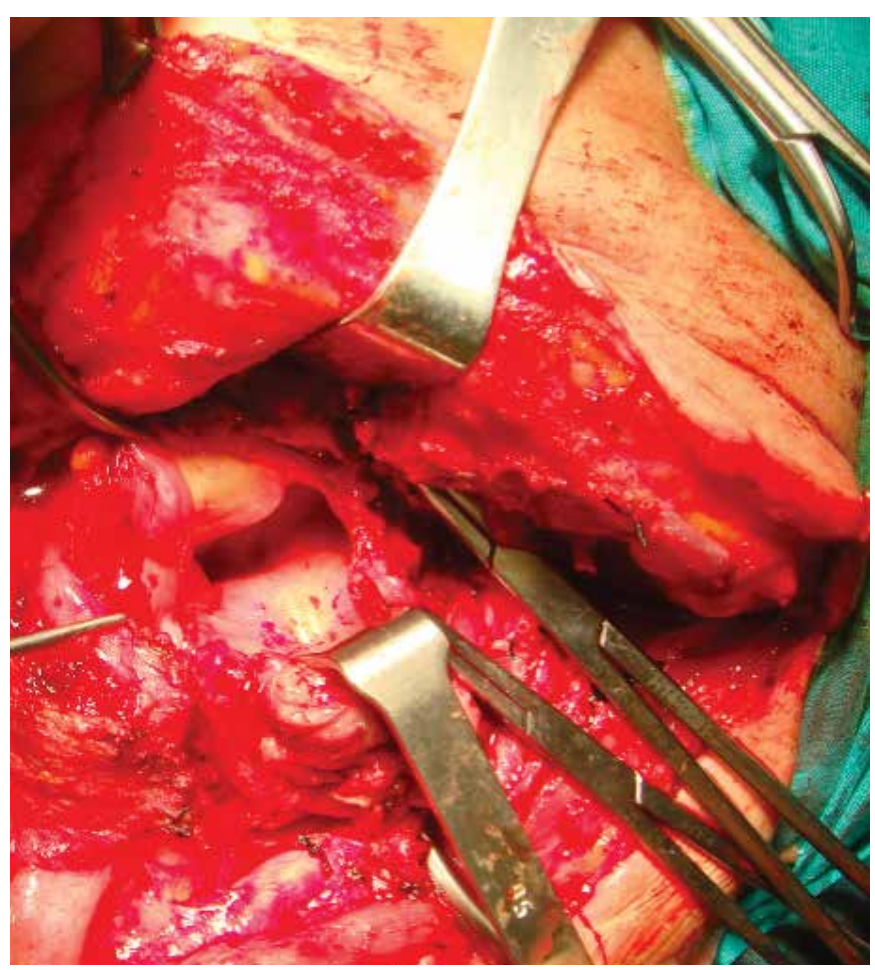

FIG. 2. The tumour was dissected upwards from the left sinus pyriformis and the great horn of the thyroid cartilage through the retropharyngeal space to the parapharyngeal space and the base of the skull.

\section{DISCUSSION}

Papillary carcinoma is the most common malignancy of the thyroid gland and peaks during the middle decades of life, with excellent overall survival rates. Despite the high survival rates, small subgroups of patients have poor outcomes due to metastasis. The pattern of spread is usually through the lym-

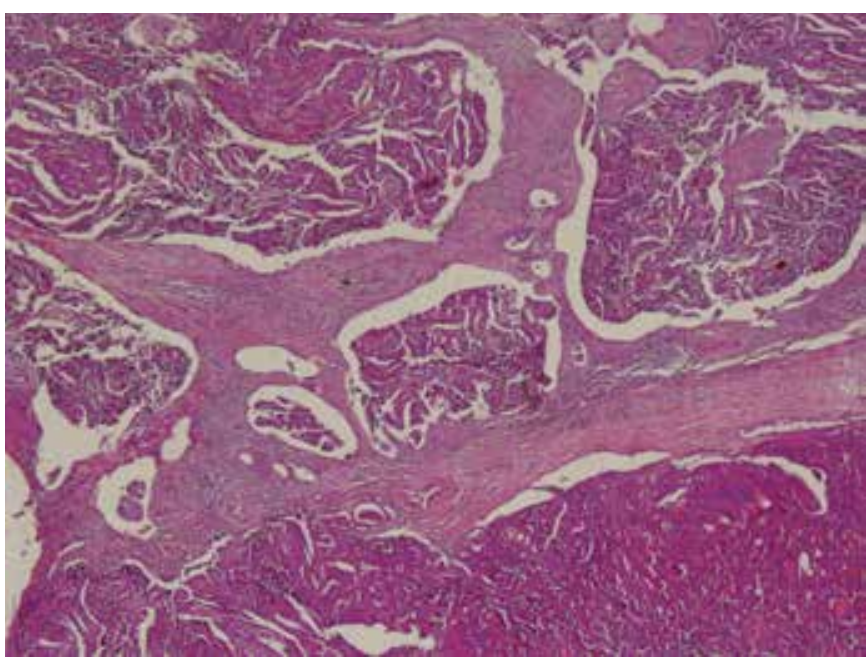

FIG. 3. The diagnosis was reported as papillary carcinoma metastasis.

phatic system; vascular spread is rare, but when it occurs, it usually metastasises to the bone, brain, lungs, and soft tissue. The involvement of other structures in the neck commonly occurs by direct infiltration of the tumour.

Tumours of the parapharyngeal space represent $0.5 \%$ of all head and neck tumours, and $20 \%$ of them are malignant $(7,8)$. Most of these neoplasms are pleomorphic adenomas derived from the deeper lobe of the parotid gland or minor salivary glands. These lesions usually arise in the pre-styloid compartment while neurogenic tumours are common in the retrostyloid compartment of the parapharyngeal space.

Carcinoma of the thyroid gland spreads to the parapharyngeal region by primitive parapharyngeal metastasis with the occult carcinoma of the thyroid glands or secondary to recurrence in the neck of a thyroid carcinoma that had been previously treated. The hypopharyngeal metastasis of the papillary carcinoma is extremely rare; only a few cases have been reported before $(8,9)$. Rouviere (10) described a lymphatic bundle connecting the posterior and superior compartments of the lateral thyroid lymph vessels to the retropharyngeal lymphatic system. According to the author, this anatomical variation was present in $20 \%$ of the cases. Other authors describe possible routes that reinforced Rouviere's opinion. Once the metastatic cells reach the retropharyngeal spaces and communicate freely with each other, the tumour cells can easily involve the parapharyngeal space. The parapharyngeal and retropharyngeal spaces lie deep in the superficial or anterior layer of the deep fascia, and communicate with each other around the muscle and vessels that pass through them. Laryngeal or hypopharyngeal carcinomas could conceivably spread to the parapharyngeal space via the same anatomical pathways that have been reported previously $(6,7)$.

Parapharyngeal masses can be difficult to examine clinically; therefore, radiological imaging methods are necessary, 
especially in patients who have undergone a previous neck dissection. Ultrasonography is a useful method for the diagnosis of thyroid diseases and lymphadenopathies in the neck, but it is unhelpful in the parapharyngeal area (11). ACT can be economical but MRI is superior for soft tissue imaging.

The effective treatment of papillary thyroid carcinoma metastases into the local area is surgical resection (12). However, when residual thyroid tissue is left behind, a postoperative beam radiotherapy or radioablation are worth considering (8).

Thyroid metastases to the parapharyngeal space are often reported in the literature $(4,7,8)$. One case with orbital metastasis (13) and one case of both larynx and hypopharynx metastasis have been reported (8). In this case, we present a patient who had undergone a total thyroidectomy with papillary thyroid carcinoma diagnosis and a left modified radical neck dissection with an interval of 8 years and presented a hypopharyngeal and parapharyngeal metastasis two years after the neck dissection.

In conclusion, lymphatic and vascular metastases of papillary thyroid carcinoma separately to the parapharyngeal space and hypopharynx have rarely been reported. In our case, both hypopharyngeal and parapharyngeal space involvement were present, which is a very rare condition.

Ethics Committee Approval: Ethics committee approval was received for this study.

Informed Consent: Written informed consent was obtained from patient who participated in this study.

Peer-review: Externally peer-reviewed.

Author contributions: Concept - A.B.K., E.A. H.C.; Design - A.B.K., E.A., H.C.; Supervision - Ö.Y., H.C., A.B.K.; Resource - A.B.K., E.A., İ.E.; Materials - A.B.K., E.A., İ.E.; Data Collection\&/or Processing - A.B.K., E.A.,H.C.; Analysis\&/or Interpretation - A.B.K., Ö.Y., H.C.; Literature Search - A.B.K., E.A., İ.E.; Writing - A.B.K., E.A., H.C.; Critical Reviews - A.B.K., Ö.Y., H.C.
Conflict of Interest: No conflict of interest was declared by the authors.

Financial Disclosure: The authors declared that this study has received no financial support.

\section{REFERENCES}

1. Kebebew E, Clark OH. Differentiated thyroid cancer: "complete" rational approach. World J Surg 2000;24:942-51. [CrossRef]

2. Cotran RD, Kumar V, Collins T. Robbins pathological basis of disease. Philadelphia: WB Saunders Company; 1999:1143-4.

3. Shaha AR, Shah JP, Loree TR. Patterns of nodal and distant metastasis based on histologic varieties in differentiated carcinoma of the thyroid. Am J Surg 1996;172:692-4. [CrossRef]

4. McCaffrey TV, Bergstralh EJ, Hay ID. Locally invasive papillarythyroid carcinoma. Head Neck 1994;16:165-72. [CrossRef]

5. Cooney BS, Levine MS, Schnall MD. Metastatic thyroid carcinoma presenting as an expansile intraluminal esophageal mass. Abdom Imaging 1995;20:20-2. [CrossRef]

6. Ferrario F, Roselli R, Machhi A. Occult thyroid carcinoma presenting as a parapharyngeal mass. J Laryngol Otol 1995;109:1204-6. [CrossRef]

7. Pearlman SJ, Lawson W, Biller HF. Occult medullary carcinoma of the thyroid presenting as neck and parapharyngeal metastases. Otolaryngol Head Neck Surg 1988;99:509-12.

8. Varghese B, Mathews A, Pandey M, Pradeep VM. Unusual metastasis of papillary thyroid carcinoma to larynx and hypopharynx a case report. World J Surg Oncol 2003;1:7. [CrossRef]

9. Hakeem AH, Pradhan SA, Bhele S, Tubachi J. Metastasis of papillary thyroid cancer to the larynx and pharynx: unusual case report. Eur Arch Otorhinolaryngol 2012; 269:2585-7. [CrossRef]

10. Rouviere H. Anatomy of the human lymphatic system. In: Tobias, MJ, editor. Anatomy of the human lymphaticsystem. Michigan: Edward Bros; 1938.

11. Wang XL, Xu ZG, Wu YH, Liu SY, Yu Y. Surgical management of parapharyngeal lymph node metastasis of thryoid carcinoma: a retrospective study of 25 patients. Chin Med J (Engl) 2012;125:3635-9.

12. Desuter G, Lonneux M, Plouin-gaudon I, Jamar F, Coche E, Weynand B. Parapharyngeal metastases from thyroid cancer. Eur J Surg Oncol 2004;30:80-4. [CrossRef]

13. Filho FDR, Lima GG, Ferreria FVA, Lima MG, Hissa MN. Orbital metastasis as primary clinical manisfestation of thyroid carcinoma-case report and literature review. Arq Bras Endocrinol Metabol 2008;52:1497-500. 